\title{
Simple sequence repeat markers useful for sorghum downy mildew (Peronosclerospora sorghi) and related species
}

\author{
Ramasamy Perumal ${ }^{1}$, Padmavathi Nimmakayala ${ }^{4}$, Saradha R Erattaimuthu ${ }^{1}$, \\ Eun-Gyu No ${ }^{3}$, Umesh K Reddy ${ }^{4}$ Louis K Prom5 ${ }^{5}$, Gary N Odvody², \\ Douglas G Luster ${ }^{6}$ and Clint W Magill*1
}

\begin{abstract}
Address: ${ }^{1}$ Department of Plant Pathology and Microbiology, Texas A\&M University, College Station, Texas - 77843-2132, USA, ${ }^{2}$ Department of Plant Pathology and Microbiology, Texas Agrilife Sciences, Corpus Christi, Texas - 78406-1412, USA, ${ }^{3}$ Institute for Plant Genomics \& Biotechnology, Texas A\&M University, College Station, Texas - 77843-2123, USA, ${ }^{4}$ West Virginia State University, Institute, Department of Biology and Gus R. Douglas Institute, WV - 25112, USA, ${ }^{5}$ USDA-ARS, Southern Plains Agricultural Research Center, College Station, Texas - 77845, USA and ${ }^{6}$ USDA/ARS, Foreign Disease-Weed Science Research Unit, Ft. Detrick, Maryland - 21702, USA
\end{abstract}

Email: Ramasamy Perumal - rperumal@ag.tamu.edu; Padmavathi Nimmakayala - padma@wvstateu.edu;

Saradha R Erattaimuthu - saradha64@neo.tamu.edu; Eun-Gyu No - e-no@tamu.edu; Umesh K Reddy - ureddy@wvstateu.edu; Louis K Prom - Louis.Prom@ARS.USDA.GOV; Gary N Odvody - g-odvody@tamu.edu; Douglas G Luster - doug.luster@ars.usda.gov; Clint W Magill* - c-magill@tamu.edu

* Corresponding author

Published: 29 November 2008

BMC Genetics 2008, 9:77 doi:10.1 186/147|-2156-9-77
Received: 7 August 2008

Accepted: 29 November 2008

This article is available from: http://www.biomedcentral.com/I47I-2/56/9/77

(c) 2008 Perumal et al; licensee BioMed Central Ltd.

This is an Open Access article distributed under the terms of the Creative Commons Attribution License (http://creativecommons.org/licenses/by/2.0), which permits unrestricted use, distribution, and reproduction in any medium, provided the original work is properly cited.

\begin{abstract}
Background: A recent outbreak of sorghum downy mildew in Texas has led to the discovery of both metalaxyl resistance and a new pathotype in the causal organism, Peronosclerospora sorghi. These observations and the difficulty in resolving among phylogenetically related downy mildew pathogens dramatically point out the need for simply scored markers in order to differentiate among isolates and species, and to study the population structure within these obligate oomycetes. Here we present the initial results from the use of a biotin capture method to discover, clone and develop PCR primers that permit the use of simple sequence repeats (microsatellites) to detect differences at the DNA level.

Results: Among the 55 primers pairs designed from clones from pathotype 3 of $P$. sorghi, 36 flanked microsatellite loci containing simple repeats, including 28 (55\%) with dinucleotide repeats and 6 (II\%) with trinucleotide repeats. A total of 22 microsatellites with CA/AC or GT/TG repeats were the most abundant (40\%) and GA/AG or CT/TC types contribute $15 \%$ in our collection. When used to amplify DNA from 19 isolates from $P$. sorghi, as well as from 5 related species that cause downy mildew on other hosts, the number of different bands detected for each SSR primer pair using a LI-COR- DNA Analyzer ranged from two to eight. Successful cross-amplification for 12 primer pairs studied in detail using DNA from downy mildews that attack maize ( $P$. maydis \& $P$. philippinensis), sugar cane (P. sacchari), pearl millet (Sclerospora graminicola) and rose (Peronospora sparsa) indicate that the flanking regions are conserved in all these species. A total of I5 SSR amplicons unique to $P$. philippinensis (one of the potential threats to US maize production) were detected, and these have potential for development of diagnostic tests. A total of 260 alleles were obtained using 54 microsatellites primer combinations, with an average of 4.8 polymorphic markers per SSR across 34 Peronosclerospora, Peronospora and Sclerospora spp isolates studied. Cluster
\end{abstract}


analysis by UPGMA as well as principal coordinate analysis (PCA) grouped the 34 isolates into three distinct groups (all 19 isolates of Peronosclerospora sorghi in cluster I, five isolates of $P$. maydis and three isolates of $P$. sacchari in cluster II and five isolates of Sclerospora graminicola in cluster III).

Conclusion: To our knowledge, this is the first attempt to extensively develop SSR markers from Peronosclerospora genomic DNA. The newly developed SSR markers can be readily used to distinguish isolates within several species of the oomycetes that cause downy mildew diseases. Also, microsatellite fragments likely include retrotransposon regions of DNA and these sequences can serve as useful genetic markers for strain identification, due to their degree of variability and their widespread occurrence among sorghum, maize, sugarcane, pearl millet and rose downy mildew isolates.

\section{Background}

Sorghum (Sorghum bicolor) is the world's $5^{\text {th }}$ most important grain crop [1], and with a genome much smaller than maize, is a model for tropical grasses of worldwide importance. It is a major source of food, feed, fiber, fuel, and chemical feed stocks across a range of environments and production systems. However, diseases and insects, in addition to abiotic stresses, are major impediments to sorghum production. Among the diseases, sorghum downy mildew (SDM), caused by Peronosclerospora sorghi, [2] is a disease of sorghum and maize (Zea mays) [3]. SDM can cause severe epidemics, resulting in heavy yield loss. In the past $P$. sorghi has been subdivided into 'sorghum/ maize' and 'maize' infecting strains. As more information has become available, the Peronoscleosporas have been designated as separate species, with names that indicate the preferred host ( $P$. maydis on maize and P. sacchari for sugarcane). Although $P$. sorghi can produce symptoms on both maize and sorghum, it typically does not complete sexual reproduction on maize, so no oospores are formed. Sorghum and maize downy mildew ( $P$. sorghi) reported in 44 countries and pearl millet downy mildew (Sclerospora graminicola) reported in 51 countries around the globe are found in most tropical and subtropical regions [4,5]. These oomycetes are both seed and soil-borne pathogens, thus rendering crop rotation less effective in controlling the disease. A sudden re-emergence and disease outbreak of sorghum downy mildew resulting in significant yield loss was noted in Wharton and Jackson counties of Texas during the spring of 2001 and again in 2002 [6]. P. sorghi isolates from the outbreak were found to be resistant to metalaxyl [methyl N- (2, 6-dimethylphenyl)-N-(methoxyacetyl)-DL-alaninate] fungicide, which had been used as an effective seed treatments for many years. Subsequently, isolates collected from previously resistant hosts revealed the evolution of a new pathogenic race of $P$. sorghi and demonstrated a need for constant monitoring of the pathogen populations.

Philippine downy mildew of maize, caused by Peronosclerospora philippinensis (Weston) C.G. Shaw, has not been reported in the western hemisphere, but it is a serious problem in the Philippines where disease losses in some fields have been 40-60\% [7]. Although maize varieties resistant to $P$. philippinensis have been developed in Asia, maize hybrids currently grown in the United States are highly susceptible to P. philippinensis and American breeding lines that are highly resistant to $P$. sorghi in the United States are generally susceptible to P. philippinensis (M.R. Bonde, personal communications). Besides maize and sorghum [8], P. philippinensis has been reported to infect Avena sativa L., Saccharum officinarum L., Sorghum halepense (L.) Pers, S. propinquum (Kunth) Hitchc. [9] and Saccharum spontaneum L. [10]. Consequently, P. philippinensis is the subject of quarantine in many countries and was listed by USDA APHIS under CFR 7 part 331 as a "select agent" in the US, meaning it is considered to be a major threat to agricultural security. Because of the threat posed by $P$. philippinensis, a DNA sample available from the USDA, ARS Foreign Disease-Weed Science Research Unit at Ft. Detrick, MD was included in this study. The information gained, besides having epidemiologic significance for maize and sorghum production, also could help resolve confusion over the taxonomy of Peronosclerospora spp.

The population structure of $P$. sorghi has been previously addressed with physical characters, such as spore size or pathotype, which require comparative disease responses on a series of host differential cultivars $[11,12]$. Conventional methodologies for the detection of different pathotypes of downy mildews of cereals have not been satisfactory particularly for the identification of organisms at extremely low propagule numbers and are cumbersome for use with obligate parasites (such as plant-pathogenic rusts and mildews), which cannot be cultured. Hence, in tropical climates, symptoms of Peronosclerospora can be confused with those from related downy mildew pathogens, including $P$. maydis, $P$. sacchari and $P$. philippinesis. Yao et al. [13] showed that clones of P. sorghi DNA crosshybridized well on Southern blots with DNA from the other Peronosclerospora species. While few differences were detected among the RFLP patterns within P sorghi, different patterns were seen for the different species. Similarly, ITS-2, an internal transcribed spacer of ribosomal genes 
was different in size [14]. While potentially useful in species identification, more easily scored and highly variable markers from locations throughout the genome are needed for differentiating among closely related pathotypes, and to tag genes that contribute to host specificity, race specificity, and virulence. Although polymorphisms were detected in SDM pathotypes using RAPD-PCR, many of the short (10 mer) primers resulted in monomorphic banding patterns. A larger problem involved inconsistently amplified bands that varied greatly in intensity, even in duplicate experiments [15]. As a consequence, a more consistent procedure was sought in the present investigation for the development of microsatellite markers.

Simple sequence repeat (SSR), or microsatellites, are hypervariable and dispersed in the form of long arrays of short tandem repeat units throughout the genome $[16,17]$. These SSRs provide codominant Mendelian markers, much more powerful than dominant markers and can be used to determine population genetic structure, kinship, reproductive mode, and genetic isolation $[18,19]$. When compared with several other marker types, SSR markers were superior for genetic characterization in Aspergillus fumigatus, and in Saccharomyces cerevisiae $[20,21]$. Microsatellite markers have been developed for several fungi including Magnaporthe grisea [22,23], and another oomycete, Phytophthora infestans [24] among others. However, based on sequence searches using genome data P. infestans and two other plant pathogenic Phytophthoras, potential SSRs have been reported to be rare [25].

In the present study, many new microsatellite sequences comprised of dinucleotide and trinucleotide repeat structures were retrieved from genomic DNA of Sorghum Downy Mildew (Peronosclerospora sorghi) pathotype 3 using an optimized and highly simplified biotin capture protocol. On the basis of sequence analysis of these captured fragments, appropriate primers were designed for amplification of these microsatellite loci and the developed microsatellites for $P$. sorgh $i$ were tested for the ability to differentiate pathogenically diverse isolates of $P$. sorghi and for their utility for cross-species amplification in $P$. philippinensis, P. maydis (maize), P. sacchari (sugar cane), Sclerospora graminicola (pearl millet) and Peronospora sparsa (rose) downy mildew. Clustering analysis was performed to assess the genetic diversity and close relatedness among 34 isolates including the different species of downy mildews.

\section{Methods}

\section{Pathogen samples and DNA isolation}

A total of 19 isolates of Peronosclerospora sorghi including P1 (metalaxyl susceptible), P3 and P6 (both metalaxyl resistant and susceptible) pathotypes collected in different years from different parts of Texas where the disease out- burst occurred were included in this study. In addition, DNA samples from P. philippinensis (one), P. maydis (five), P. sacchari (three) were obtained from Dr. Douglas G. Luster, USDA/ARS, Foreign Disease-Weed Science Research Unit, Ft. Detrick, Maryland, USA and DNA samples of Sclerospora graminicola (five) and Peronosopora sparsa (one) available in Dr. Magill's lab, Dept. of Plant Pathology \& Microbiology, Texas A\&M University, College Station, Texas, USA, were also included in the present study (Table 1). For DNA isolation, conidia were collected from infected leaves as follows: leaves were washed with cold sterile water and placed abaxial side down on a screen in a petri plate, covered with moist paper towels and allowed to sporulate in the dark overnight at $23^{\circ} \mathrm{C}$ [26]. Spores collected in sterile water were used for DNA extraction. After removing excess water, conidial suspensions were washed a few times with $70 \%$ ethanol and frozen for lyophilization. The dried sample was powdered in liquid nitrogen using a mortar and pestle. DNA was extracted using a MasterPure Yeast DNA Purification kit (EPICENTRE Biotechnologies, Madison, WI) and the DNA was diluted to working concentration of $2.5 \mathrm{ng} / \mu \mathrm{L}$ by adding $1 \times$ TE (10 m M Tris-HCl, 1 mM EDTA, pH 8.0).

\section{Microsatellite Isolation}

A microsatellite-enriched library was prepared by a simplified protocol based on the biotinylated-oligonucleotide capture methods of [27] and [28]. Further, several steps in the biotin capture protocol were modified as detailed by Reddy et al. [29] to optimize the frequency of microsatellite repeats among captured genomic DNA fragments. In our protocol, no size fractionation steps or radioactive hybridizations were employed. A $500 \mathrm{ng}$ sample of genomic DNA from SDM pathotype 3 was digested for $3 \mathrm{~h}$ in a single reaction mixture containing restriction endonucleases HaeIII, RsaI, and DraI (20 units of each), as well as $50 \mathrm{ng}$ of RNaseA. This digestion resulted in a diverse population of blunt-ended restriction fragments with an average size of 550 bp. Digested DNAs were purified using a QIA-quick PCR purification column (Qiagen, Valencia, CA), eluted with $50 \mu \mathrm{l}$ of $5 \mathrm{mM}$ Tris-pH 8.0, then dried completely under vacuum. The doublestranded adaptor molecule AP11/12 was prepared by mixing equal molar amounts of oligonucleotides AP11 (5'CTCTTGCTTAGATCTGGACTA3') and AP12 (5'pTAGTCCAGATCTAAGCA-AGAGCACA3', where $\mathrm{p}=5^{\prime}$ phosphate), heating to $94^{\circ} \mathrm{C}$, then cooling to $25^{\circ} \mathrm{C}$ over a period of $5 \mathrm{~h}$. Digested genomic DNA fragments were resuspended in a 30- $\mu \mathrm{L}$ ligation reaction containing 100 ng of AP11/12 double-stranded adaptor and 30 Weiss units of T4 DNA ligase. Ligation was carried out at $14^{\circ} \mathrm{C}$ for $16 \mathrm{~h}$. Preamplification of adaptor-ligated products was performed using $2 \mu \mathrm{L}$ of the ligation reaction as a template for 10 cycles of PCR in a $50-\mu \mathrm{L}$ reaction volume using the 
Table I: Downy mildew isolates of Peronosclerospora, Sclerospora and Peronospora spp analyzed in this study

\begin{tabular}{|c|c|c|c|c|}
\hline \multicolumn{5}{|c|}{ Peronosclerospora sorghi - Sorghum downy mildew isolates } \\
\hline Iso. No & Pathotype/DNA & Metalaxyl reaction & Host & Location \& year \\
\hline I & $\mathrm{PI}$ & Sensitive & Tx7978-sorghum & Green house, TAMU, TX \\
\hline 2 & P3 & Sensitive & Tx430-sorghum & Green house, TAMU, TX \\
\hline 3 & P3 & Sensitive & Whart-A-sorghum & Wharton County, TX - 200I \\
\hline 4 & P3 & resistant & CR $360 \mathrm{~A}$ - sorghum & Wharton County, TX - 2002 \\
\hline 5 & P3 & resistant & CR 459A - sorghum & Wharton County, TX - 2002 \\
\hline 6 & P3 & resistant & Fucik B - sorghum & Wharton County, TX - 2002 \\
\hline 7 & P3 & resistant & Merta A - sorghum & Wharton County, TX - 2002 \\
\hline 8 & P3 & resistant & Wesla A - sorghum & Weslaco, TX - 2002 \\
\hline 9 & $\mathrm{P} 3$ or $\mathrm{P} 6$ & resistant & Grain sorghum & Wharton County, TX - 2004 \\
\hline 10 & P6 & resistant & Johnson grass & Jackson county TX - 2007 \\
\hline 12 & P6 & resistant & Grain sorghum & Wharton County, TX - 2007 \\
\hline 13 & P6 & resistant & Grain sorghum & Wharton County, TX - 2006 \\
\hline 14 & P3 & resistant & Grain sorghum & Wharton County, TX - 2006 \\
\hline 15 & $\mathrm{P} 3$ or $\mathrm{P} 6$ & resistant & Grain sorghum & Wharton County, TX - 2006 \\
\hline 16 & $\mathrm{PI}$ & Unknown & Johnson grass & Nueces county, TX - 2007 \\
\hline 17 & P6 & resistant & Johnson grass & Wharton county, TX - 2007 \\
\hline 18 & P6 & resistant & Grain sorghum & Wharton county, TX - 2006 \\
\hline 19 & $\mathrm{P} 3$ or $\mathrm{P} 6$ & resistant & Grain sorghum & Jackson county, TX - 2006 \\
\hline 21 & $\mathrm{PI}$ & Sensitive & Grain sorghum & Nueces county, TX - 2007 \\
\hline
\end{tabular}

Peronosclerospora maydis - Maize downy mildew isolates $\S$

\begin{tabular}{llcll}
\hline 22 & DNA \# 5 & - & Corn & Suwan Farm, Thailand-1975 \\
\hline 23 & DNA \# 6 & - & Corn & Malang, Indonesia - I987 \\
\hline 24 & DNA \#. 7 & - & Corn & West Java, Indonesia - 1987 \\
\hline 25 & DNA \#. 8 & - & Corn & Suwan Farm, Thailand- I985 \\
\hline 26 & DNA \# 9 & - & Corn & Suwan Farm, Thailand-1985
\end{tabular}

Peronosclerospora philippinensisisolate§

27 DNA\#. I - $\quad$ Corn L L Banos, Phillippines, 1979 
Table I: Downy mildew isolates of Peronosclerospora, Sclerospora and Peronospora spp analyzed in this study (Continued)

\begin{tabular}{|c|c|c|c|}
\hline \multicolumn{4}{|c|}{ Peronosclerospora sacchari - Sugarcane downy mildew isolates§ } \\
\hline 28 & DNA \# 2 & Race I - Sugar cane & China - 1975 \\
\hline 29 & DNA \# 3 & Sugar cane & Taiwan - 1975 \\
\hline 30 & DNA \# 4 & Isolate 77B-SCI - Sugar cane & Taiwan - 1977 \\
\hline \multicolumn{4}{|c|}{ Peronospora sparsa - Rose downy mildew isolate } \\
\hline 31 & DNA\#I & Infected Rose plant & Dis. Diagno. Lab, TAMU, TX \\
\hline \multicolumn{4}{|c|}{ Schlerospora graminicola - Pearl millet downy mildew isolates* } \\
\hline 32 & DNA \#6 & cultivar GK 1004 - Pearl millet & Kennola, A'bad Dt, India \\
\hline 34 & DNA \#37 & cultivar MLPH I04 - Pearl millet & Vadagaon, A'nagar Dt., India \\
\hline 36 & DNA \#42 & Local cultivar - Pearl millet & Kawdiyal, Bidar Dt., India \\
\hline 37 & DNA \#16 & cultivar Proagro - Pearl millet & Hatnur, A'bad Dt., India \\
\hline 38 & DNA \#20 & Cultivar Vijay-4-Pearl millet & Parola, Jalgoan Dt., India \\
\hline
\end{tabular}

* Sporangial isolates 32 through 38 collected from different locations in major pearl millet growing areas in Maharastra, India, Aug. 1999 and were received through ICRISAT (International Crop Research Institute for Semi-Arid Tropics), Patancheru - Hyderabad 502 324, India.

$\S$ DNA samples received from USDA/ARS, Foreign Disease-Weed Science Research Unit, Ft. Detrick, MD 21702.

single primer AP11. An annealing temperature of $55^{\circ} \mathrm{C}$ was employed in all PCR reactions.

Approximately $100 \mathrm{ng}$ of the preamplified product was then added to a single reaction mixture containing $6 \times$ SSC $(0.9 \mathrm{M} \mathrm{NaCl}, 90 \mathrm{mM}$ sodium citrate, $\mathrm{pH}$ 7), 0.1\% SDS (sodium dodecyl sulfate), and 200 ng each of biotinylated oligos b(TA)30, b(CA)20, b(GA)20, and b(AGA)15, b(TGA)15, b(ACA)15, (b = 5' biotinylation). After denaturation at $95^{\circ} \mathrm{C}$ for $5 \mathrm{~min}$, preamplified genomic DNA fragments were annealed in the presence of biotinylated oligonucleotides for $1 \mathrm{~h}$ at $60^{\circ} \mathrm{C}$, then added to $200 \mu \mathrm{g}$ of fresh streptavidin-coated paramagnetic beads (Promega, Madison, WI) previously equilibrated with $6 \times$ SSC. Beads were incubated at $60^{\circ} \mathrm{C}$ with gentle agitation for $15 \mathrm{~min}$, then the liquid was removed by separation using a magnetic stand (Stratagene, San Diego, CA). Beads were washed twice in $300 \mu \mathrm{L}$ of $6 \times$ SSC, $0.1 \%$ SDS for $15 \mathrm{~min}$ at room temperature with gentle agitation. Beads were further washed twice in $300 \mu \mathrm{L} 6 \times$ SSC, $0.1 \%$ SDS for $15 \mathrm{~min}$ at $60^{\circ} \mathrm{C}$ with gentle agitation. Finally, beads were briefly washed twice with $6 \times$ SSC at room temperature. After removing the final wash, captured DNAs were eluted from the beads with the addition of $100 \mu \mathrm{L}$ of $60^{\circ} \mathrm{C} 0.1 \mathrm{M}$ $\mathrm{NaOH}$. After neutralization with $100 \mu \mathrm{L}$ of $1 \mathrm{M}$ Tris-pH 7.5, captured DNAs were desalted and equilibrated with $10 \mathrm{mM}$ Tris-pH 8.0, $1 \mathrm{mM}$ EDTA-pH 8.0 (to a final vol- ume of $\sim 50 \mu \mathrm{L}$ ) using a 100-kDa MW cutoff size filtration column (Millipore, Bedford, MA). Five $\mu \mathrm{L}$ of desalted DNA sample were used as a template for 30 cycles of PCR in a $50-\mu \mathrm{L}$ reaction volume using primer AP11. Six microliters of the resulting PCR reaction ( $~ 60 \mathrm{ng}$ ) was cloned into the TA-cloning vector pCR4-TOPO through topoisomerase mediated ligation (Invitrogen, San Diego, CA) and transformed into chemically competent Escherichia coli TOPO10. Recombinant colonies were identified by positive selection through insertional inactivation of the $c c d \mathrm{~B}$ (control of cell death) open reading frame. Colonies were transferred to 96-well microtiter plates for archival storage.

\section{Sequence Analysis}

Recombinant bacterial colonies were inoculated into 300 $\mu \mathrm{L}$ of LB amp media in a 96-well 0.6-mL-deep plate (Marsh Bioproducts, Rochester, NY). Cultures were agitated at $500 \mathrm{rpm}$ in a HiGro high-density shaking-incubator (GeneMachines, San Carlos, CA) for 16 to $18 \mathrm{~h}$ at $37^{\circ} \mathrm{C}$. DNA sequencing was performed by RCA (rolling circle amplification) using Templiphi 100 Amplification Kit (GE Healthcare Bio-Sciences Co. Piscataway, NJ). 0.5 $\mu \mathrm{l}$ of the bacteria was added into $5 \mu \mathrm{l}$ of sample buffer. The sample was denatured at $95^{\circ} \mathrm{C}$ for 3 minutes, and then cooled to room temperature or $4{ }^{\circ} \mathrm{C}$. The denatured sample was combined with $5 \mu \mathrm{l}$ of reaction buffer and 0.2 
$\mu \mathrm{l}$ enzyme mix. DNA was incubated at $30^{\circ} \mathrm{C}$ for $18 \mathrm{hrs}$ for Templiphi reaction. The amplified DNA was diluted $50 \mathrm{ul}$ of water. $2 \mathrm{ul}$ from the diluted RCA product was sequenced using BigDye terminator cycle sequencing (Perkin-Elmer Applied Biosystems, Foster City, CA) using 10 pmol of M13-forward and M13-reverse primer in a 10$\mu \mathrm{L}$ reaction. Standard cycle sequencing conditions were employed. Sequencing products were purified by DyeEX 96 kit (Qiagen, Valencia, CA). Electrophoretic separation of sequencing products was performed on an ABI Prism 3130xl Genetic Analyzer (Applied Biosystems, Foster City, CA). Assembly of double-stranded DNA sequence contigs from each clone, and identification of redundancy and overlaps between clones was performed using Sequencher 3.0 (Gene Codes, Ann Arbor, MI). Microsatellite analysis for the identification of sequences with perfect and imperfect repeats and simple and compound repeat motifs were identified using Simple Sequence Repeat Identification Tool (SSRIT) database [30].

\section{Sequence homology search}

The sequences of SDM microsatellites were subjected to homology searches using BLASTN against nucleotide collection (nr/nt) and Expressed Sequence Tags (est_others) at National Center for Biotechnology Information (NCBI; [31]).

Under Algorithm parameters the following options were chosen to improve the results.

\section{General parameters}

Max target sequences - 100; Short queries - automatically adjust parameters for short input sequences; Expected threshold - 10 \& Word size - 11

\section{Scoring parameters}

Match/Mismatch scores - 2,-3; Gap costs - Existence: 5 Extension: 2

\section{Filters and Masking}

Filter - low complexity regions; species-specific repeats for fungi

Mask - Mask for lookup table only options.

\section{Design of primers and PCR amplification}

Primers were designed to the flanking region of the SSR using PRIMER 3 software[32]. Primers were designed without repetitive DNA and with a base composition of greater than $40 \% \mathrm{G}+\mathrm{C}$ with annealing temperature between $52^{\circ} \mathrm{C}$ and $58^{\circ} \mathrm{C}$ to yield amplification product between 100 and $250 \mathrm{bp}$. Oligonucleotide primers were synthesized by Integrated DNA Technologies, Coralville, IA, USA. Primers selected by these criteria were evaluated further for melting temperature, internal structure, and propensity for primer-dimer formation using publicly accessible Worldwide Web resources (Sigma-Genosys, The Woodlands, TX). PCR amplification was carried out in $10 \mu \mathrm{L}$ containing $5.5 \mathrm{ng}$ of genomic DNA, $1 \mu \mathrm{L} 10 \times$ PCR buffer (Promega), $0.8 \mu \mathrm{L}$ of $2.5 \mathrm{mM}$ dNTP mix, $1 \mu \mathrm{L}$ each of $1 \mathrm{pM} / \mu \mathrm{L}$ forward and reverse primers, $1 \mu \mathrm{L}$ of 25 $\mathrm{mM} \mathrm{MgCl}_{2}$, and $1 \mathrm{U}$ of Taq polymerase. PCR was performed for an initial denaturation of $2 \mathrm{~min}$ at $95^{\circ} \mathrm{C}$ followed by 35 cycles of $45 \mathrm{~s}$ at $95^{\circ} \mathrm{C}, 45 \mathrm{~s}$ at the appropriate annealing temperature for each microsatellite primer pair as highlighted in Table 1 and $60 \mathrm{~s}$ at $72^{\circ} \mathrm{C}$, and a final extension of $20 \mathrm{~min}$. at $72^{\circ} \mathrm{C}$.

\section{Gel Analysis}

The developed SSR primers with 4\% SFR (super fine resolution) agarose (AMRESCO, Solon, Ohio, USA) gel electrophoresis system running with $1 \times$ TBE buffer in $4{ }^{\circ} \mathrm{C}$ using circulatory cool buffer system was used for better resolution of polymorphic differences between downy mildew isolates. The SSR amplification products were also analyzed using a LI-COR-NEN ${ }^{\circledR}$ Model 4300 -dual-dye automated DNA Analyzer. Following amplification, an equal volume $(5 \mu \mathrm{l})$ of PCR products of two sets of SSRs one labeled using the IRD-700 $\mathrm{nm}$ and another with IRD$800 \mathrm{~nm}$ fluorogenic forward primer were mixed. Basic fusion dye $(2 \mu \mathrm{l})$ (LI-COR) was added to each pooled sample and the samples were denatured for $5 \mathrm{~min}$ at $95^{\circ} \mathrm{C}$. Each sample $(1 \mu \mathrm{l})$ was loaded on a $6.5 \%$ polyacrylamide gel containing $7 \mathrm{M}$ urea. Gels were cast using LICOR 25-cm plates with 0.25-mm-thick spacers and comb. Electrophoresis was performed at a constant power of 40 $\mathrm{W}$ and a constant temperature of $47.5^{\circ} \mathrm{C}$ for $2 \mathrm{~h}$.

\section{Statistical analysis}

Microsatellite fragments were scored as present $(=1)$ or absent $(=0)$ across the 34 Peronosclerospora, Peronospora and Sclerospora spp. isolates. The resulting binary matrix was used to construct a similarity matrix using the Jaccard coefficient, $\operatorname{GS}(i j)=a /(a+b+c)(17)$, where $a$ is the number of fragments shared by $i$ and $j, b$ is the number of fragments present in $i$ and absent in $j$, and $c$ is the number of bands present in $j$ and absent in $i$. Cluster analysis was performed using the unweighted pair group with arithmetic means method (UPGMA) [33]. PAUP 4.0* was used to generate 1000 bootstrap replicates for testing the reliability of the dataset and to draw a consensus tree [34]. Ordination analysis was performed to study the relatedness within a matrix by converting the pairwise distance into Eigen vectors and values. Cluster analyses, ordination analyses and the Mantel test were performed using NTSYSpc (NTSYS - for Numerical Taxonomy SYStems) version 2.1 [35].

\section{Results}

A collection of 513 colonies, picked at random from primary transformation plates, was inoculated into 96-well culture plates for high throughput sequencing. Of the 513 
clones sequenced, 170 (33\%) were redundant with other clones in the same collection. A total of 73 out of 343 clones $(21 \%)$ did not contain repeat motifs. Of the remaining 270 nonredundant clones, Sequence analysis showed that virtually all of the inserts contained microsatellite repeat motifs matching one or more of the biotinylated oligonucleotides used in the selection process. Out of 270 clones, 144 insert fragments (53\%) were truncated within, or at the end of, a microsatellite repeat. Of the remaining 126 non redundant clones with unique sequences flanking both ends of the microsatellite repeats, 55 were selected for further analysis on the basis of the following criteria: (i) the length of the microsatellite was five or greater in dinucleotide and four in trinucleotide repeat units and; (ii) the unique $5^{\prime}$ and 3 ' flanking sequences were both of suitable structure and composition for the design of efficient primers. Microsatellites with flanking sequences that were highly repetitive in nature and/or had high $\mathrm{A}+\mathrm{T}$ rich nucleotides were eliminated.

Thirty six microsatellite loci containing a simple repeat type made up $66 \%$ of the DM collection, including 28 $(55 \%)$ with dinucleotide repeat types and $6(11 \%)$ with trinucleotide repeat types (three CAA and one each of GTT, AGG and ACA). Of the microsatellites containing a simple repeat type, 94\% had "perfect" repeats (except DM9 and DM16), uninterrupted by nonrepeat nucleotides. The remaining 19 SSR loci (39\%) of the collection were composed of "compound repeats" consisting of more than one repeat type at a single locus and all were interrupted by nonrepeat nucleotides and hence considered as "imperfect" repeats (Table 2). All the compound repeats were combinations of dinucleotide repeat motifs except DM45 (trinucleotide) and DM49 (combination of tetra and dinucleotide) repeat motifs. A total of 22 microsatellites with the CA/AC or GT/TG repeat type were the most abundant (40\%) and the GA/AG or CT/TC type contributes $15 \%$ in our collection.

Of the 55 cloned SSR sequences queried in BLASTN searches of the NCBI non-redundant genomic and EST databases(as of July 4, 2008), only four clones DM21, DM28, DM53 and DM55 were found to show similarity to previous entries and these were to sequences of Phytophthora and Pythium species which are also plant pathogenic oomycetes. Details are presented in table 3 . These results indicate that two of the cloned sequences (DM53 and DM54) isolated from P. sorghi contain incomplete portions of genes found in known retrotransposon elements.

Primers were designed for the 55 selected microsatellite loci using the criteria described in materials and methods. These primers (for Table 4 see additional file 1) had an average length of 20.7 nucleotides, with an average $\mathrm{G}+\mathrm{C}$ content of $49 \%$ and annealing temperature in a range of $50-55^{\circ} \mathrm{C}$. Predicted cloned products ranged in size from 106 (DM52) to 249 (DM21) bp. These 55 new microsatellite loci described in Table 4 (see additional file 1) were designated as "DM" (Downy Mildew). One of the 55, DM15 was not amplified in any of the pathotypes when resolved either in SFR agarose or LI-COR polyacrylamide gels. DM17, 27, 40, 41, 45 and 48 were resolved with faint expression in SFR agarose gels and with fine resolution in LI-COR polyacrylamide gels. When used with 34 Peronosclerospora and Sclerospora spp isolates, a total of 260 alleles were obtained using 54 microsatellites primer combinations in LI-COR polyacrylamide gels, with an average of 4.8 polymorphic markers per SSR. In comparison, only 128 alleles were visible using 48 SSRs in SFR agarose gels with an average of 2.7 polymorphic markers per SSR across the same set of isolates. Four SSRs (DM12, 19, 30 and DM38) showed monomorphic expression in SFR agarose gels but polymorphisms were detected in LICOR poly-acrylamide gels. SFR agarose gel data for 54 SSRs across species were not used further in this study.

Of the 54 SSR primer pairs, 50 produced amplicons in Peronosclerospora sorghi, 41 in P. maydis, 29 in P. sacchari, 33 in P. philippinensis, 30 in Peronosopora sparsa and 37 in Sclerospora graminicola downy mildew isolates (Table 5). Twelve SSR primer pairs (DM 9, 12, 13, 14, 16, 19, 30, 31, $35,49,53$ and DM54) amplified products in all six species. A total of 15 (DM 3, 8, 11, 13, 18, 27, 31, 39, 40, 45, 50, 52, 53, 54, \& DM 55) and seven (DM13, 23, 24, 45, 48,50 and DM53) produced unique bands in P. philippinensis and $P$. sparsa respectively. Representative examples of

Table 2: Examples of different types of microsatelitte repeat structures identified in Peronosclerospora sorghi - pathotype. 3

\begin{tabular}{ccl}
\hline Microsatelitte loci & \multicolumn{1}{c}{ Type } & Repeat structures \\
\hline DM2 & simple and perfect repeat & GT GT GT GT GT GT GT GT \\
\hline DM16 & simple and Imperfect repeat & TG TG TG TG TG TG TG TG TG TATG TG TG TG TG TG TG TG TG TG TG TG TG TG \\
& TG TG TG TG TG TG TG TG \\
\hline DM13 & compound and imperfect & CACACACACACACACATCTGTATATATA \\
\hline
\end{tabular}

Bold and underlined are interrupted non repeat nucleotides makes the SSR loci imperfect 
Table 3: Results of BLAST Query - SDM fungal microsatellites showing homology against the NCBI database

\begin{tabular}{|c|c|c|c|c|}
\hline SSR loci & Locus, Species, \& Most related sequence (Genomic DNA/EST) & Query coverage (\%) & Identity (\%) & E-value* \\
\hline DM2I & $\begin{array}{l}\text { DQ645744, Phytophthora ramorum (Sudden oak death agent - Fungi), transposon } \\
\text { GypsyPr-2 reverse transcriptase gene - Genomic DNA }\end{array}$ & 26 & 96 & $3 e-20$ \\
\hline DM28 & AF312890, Phytophthora cinnamomi SSR sequence - Genomic DNA & 45 & 90 & $4 e-36$ \\
\hline \multirow[t]{4}{*}{ DM53 } & $\begin{array}{l}\text { DQ645744.I - Phytopthora ramorum transposon GypsyPr-2 reverse transcriptase } \\
\text { gene }\end{array}$ & 96 & 78 & $4 e-70$ \\
\hline & $\begin{array}{l}\text { AY830104, (GypsyPi-3a), AY830105 (GypsyPi-3b) Phytophthora infestans - } \\
\text { retrotransposon }\end{array}$ & 93 & 96 & $3 e-14$ \\
\hline & AF490339, Phytophthora infestans - Gypsy like retrotransposon, & 87 & 90 & $2 e-09$ \\
\hline & DQ645742, Phytophthora sojae transposon GypsyPs-IA reverse transcriptase gene & 78 & 90 & $4 e-07$ \\
\hline \multirow[t]{8}{*}{ DM55 } & AY564217, Phytophthora ipomoeae & 54 & 90 & $6 e-32$ \\
\hline & EU427470.I - P. ramorum & 52 & 89 & $3 e-30$ \\
\hline & $\begin{array}{l}\text { AY564219 - P. andina, AY564218-P. phaseoli, AY564213 to AY564216 - P. mirabilis, } \\
\text { AY564209 to AY0039II - P. infestans \&DQ8327I7 and AY564221- Phytophthora } \\
\text { sojae }\end{array}$ & 54 & 89 & $3 e-30$ \\
\hline & - mitochondrion DNA & & & \\
\hline & ES287433 and ES286374Phytophthora brassicae & 5454 & 8888 & $2 e-302 e-29$ \\
\hline & CV935202Phytophthora infestans (potato late blight) & 54 & 86 & $\mathrm{le}-26$ \\
\hline & EL774547, EL777768, EL775494, EL779446, EL78I I 47 and EL775427Pythium ultimum & & & \\
\hline & - ESTs, & & & \\
\hline
\end{tabular}

*E value or the Expect value is a parameter that describes the number of hits one can "expect" to see just by chance when searching a database of a particular size

the distinct banding differences for amplification products obtained with 34 Peronosclerospora, Peronospora and Sclerospora spp. isolates using the DM9 microsatellite primer pair are shown in Fig. 1.

A presence (1) or absence (0) binary matrix containing 260 clear amplicons from 54 SSRs was used to generate the genetic similarity estimates. The similarity co-efficient ranged from 0.77 to 0.98 indicating narrow genetic distance among the isolates of the different species studied.
The dendrogram constructed using UPGMA (Fig. 2) summarizes the interrelationship observed among 34 isolates of different downy mildew species. With the similarity coefficient greater than 0.84 , all the 34 isolates were grouped into three distinct clusters. In the cluster I, 18 Peronosclerospora sorghi isolates including pathotype P3 (metalaxyl sensitive) and other metalaxyl resistant isolates of P3 and P6 pathotypes were all grouped together with a confidence limit of $80 \%$. Within cluster I, Metalaxyl sensitive isolates of P1 pathotype (\#1, 16 and 21 from Fig. 2)

Table 5: Amplification details of all 54 SSR loci in different downy mildew species

\begin{tabular}{|c|c|c|c|c|c|}
\hline Peronosclerospora. Sorghi & P. maydis & P. sacchari & P. philippinesis & Peronospora sparsa & Sclerospora graminicola \\
\hline $\begin{array}{l}\text { DM I, 2, 3, 4, 5, 6, 7, 8, } \\
9,10,11,12,13,14, \\
16,17,18,19,20,21, \\
22,23,24,25,26,27, \\
28,30,31,32,33,34, \\
35,36,38,40,42,43, \\
44,45,46,47,48,49, \\
50,51,52,53,54, \& \text { DM } \\
55\end{array}$ & $\begin{array}{l}\text { DM I , 5, 6, 7, } 8, \\
9,11,12,13 \\
14,16,19,20 \\
21,23,24,26, \\
27,28,30,31 \\
32,33,34,35 \\
36,37,38,40 \\
41,43,44,45 \\
46,47,49,51 \\
52,53,54, \& \\
\text { DM } 55\end{array}$ & $\begin{array}{l}\text { DM 5, 7, 8, 9, 12, 13, 14, } \\
16,17,19,23,26,28,29 \\
30,31,33,34,35,37,38 \\
43,47,49,51,52,53,54, \& \\
\text { DM } 55\end{array}$ & $\begin{array}{l}\text { DM } 3^{*}, 5,7 \\
8^{*}, 9,10, \\
11 *, 12,13^{*}, \\
14,16,18^{*}, \\
19,22,26 \\
27^{*}, 28,30 \\
31^{*}, 33,35 \\
39^{*}, 40^{*}, 44 \\
45^{*}, 46,47 \\
49,50^{*}, 52^{*} \\
53^{*}, 54^{*}, \& \\
\text { DM } 55^{*}\end{array}$ & $\begin{array}{l}\text { DM 2, 3, 7, 9, I2, 13*, 14, } \\
16,17,19,20,22,23^{*}, 24^{*} \\
25,27, \mathbf{3 0}, \mathbf{3 1}, \mathbf{3 5}, 36,40,41 \\
43,45^{*}, 48^{*}, \mathbf{4 9}, 50^{*}, 51 \\
\text { 53*, \& DM 54 }\end{array}$ & $\begin{array}{l}\text { DM 2, 3, 4, 8, 9, 10, } \\
11,12,13,14,16, \\
17,18,19,20,22,23, \\
25,27,29,30,31, \\
35,37,38,39,40,42, \\
45,46,48,49,51,52, \\
53,54, \& \text { DM } 55\end{array}$ \\
\hline Total: 50 & 41 & 29 & 33 & 30 & 37 \\
\hline
\end{tabular}

Primers in bold letters are cross- amplified in all species

* Primer combinations expressed unique bands differences from other species 


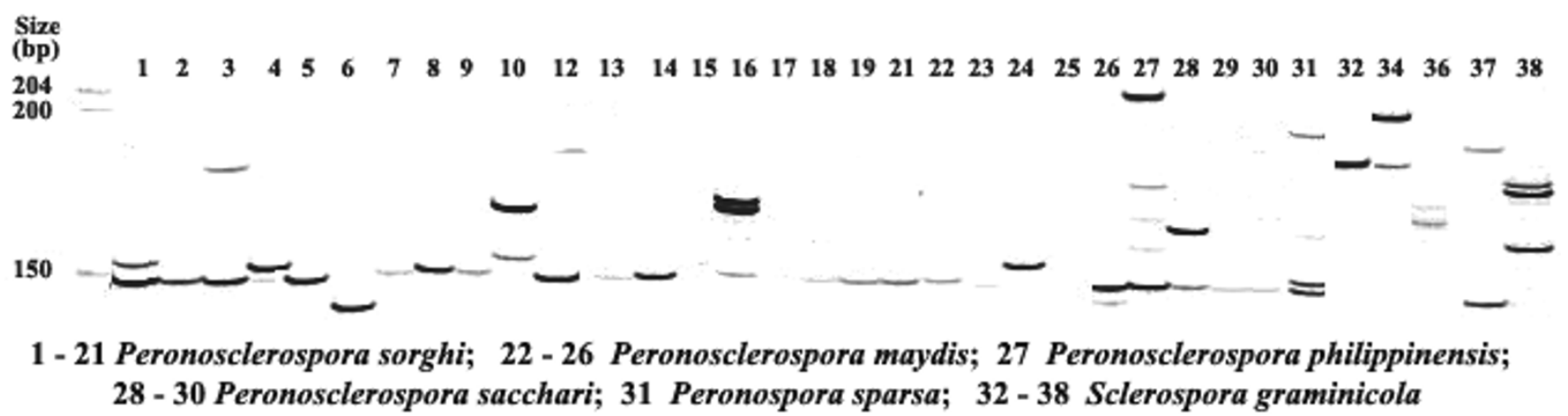

\section{Figure I}

Licor gel image of $\mathbf{3 4}$ isolates of different downy mildew species using DM 9 SSR primers. Simple sequence repeat polymorphism fingerprint of 34 isolates of different species of Peronosclerospora, Peronospora and Sclerospora after amplification with SSR primers of DM 9. Lanes I through 38 represent the downy mildew isolates of different species encoded in table I. Molecular weights are indicated in base pairs to the left.

were distinctly separated from others with a confidence limit of $79 \%$ and $76 \%$. Five isolates of $P$. maydis and three isolates of $P$. sacchari were grouped in two sub clusters with confidence limits of 83 and $74 \%$ respectively in cluster II and five isolates of Sclerospora graminicola were grouped in cluster III with confidence limit of $70 \%$. The remaining $P$. sparsa and $P$. philippinensis isolates were not grouped into any of these three clusters and showed their distinct uniqueness from other species. Principal coordinate analysis (PCA) was also performed to show the relationship among the 34 isolates as a three dimensional display. In this analysis the first two principal components (having eigen value $>1$ ) explained $86 \%$ of the total variation. Like the UPGMA clustering dendrogram, PCA analysis placed isolates of different species of downy mildew into distinct positions (Fig. 3).

\section{Discussion}

The Peronosclerospora spp. that cause downy mildew of sorghum and maize and other gramineous hosts include some of the most destructive pathogens in the tropics and subtropics [36] and some of them infect more than one important crop. Of the 10 recognized species of fungi that cause downy mildew diseases of maize, 5 currently are in the genus Peronosclerospora $[37,38]$. The confusion over nomenclature of specific pathogens involved in these diseases is a major problem in global evaluation of the downy mildews caused by Peronosclerospora. It is difficult to determine if research results and disease control methods developed in one area of the world might be applicable to another. In several instances, taxonomy within the genus is confused because, at most, only slight differences in morphology of recognized species exist [39]. With the result of traditional approaches [40] combined with utilizing molecular techniques including isozyme analysis [41] and PCR (Polymerase Chain Reaction, [14]) the maize strain of $P$. sorghi from Thailand was given specific rank as $P$. zeae [13]. Legg [42] has outlined the advantages of some of the molecular methods for studying the Peronosclerospora spp. A maize strain of $P$. sorghi was reported in southern Nigeria [43]. However, Yao et al. [14] using PCR, were unable to differentiate an isolate of SDM from maize in southern Nigeria from sorghum/maize-infecting strains and the identity of this pathogen remains unknown. The problems described warrant development of simple and powerful molecular diagnostic tools for constant monitoring of this disease. Since microsatellite regions are highly mutable due to their propensity of addition and deletion of repeat copies they can be used to differentiate within and between related taxa, even at the level of individual isolates in a single species. Simple DNA- profiling methods based on microsatellite variability provide possibilities to identify individual genotypes for studies in population genetics, ecology and taxonomy [44].

\section{Characterization of microsatellite loci}

In the present study, a total of 55 microsatellite loci were isolated from Peronosclerospora sorghi - pathotype P3 DNA enriched for simple sequence motifs. We observed 33\% internal redundant motifs, likely consequences of using two PCR amplification steps during the isolation process. Of the sequenced clones with an insert, over $79 \%$ contained microsatellites. This is a significant enrichment as compared to traditional microsatellite isolation protocol [45]. However, the relatively small fragment size average resulting from the use of three restriction enzymes in the initial fragmentation (HaeIII, (GGCC) targets, RsaI, (GTAC) and DraI (AAATTT)) may explain why 144 insert fragments out of 270 clones (53\%) were truncated within, or at the end of, a microsatellite repeat. This result is in accordance with the CM collection [46], in which genomic DNAs were mechanically fragmented using a 


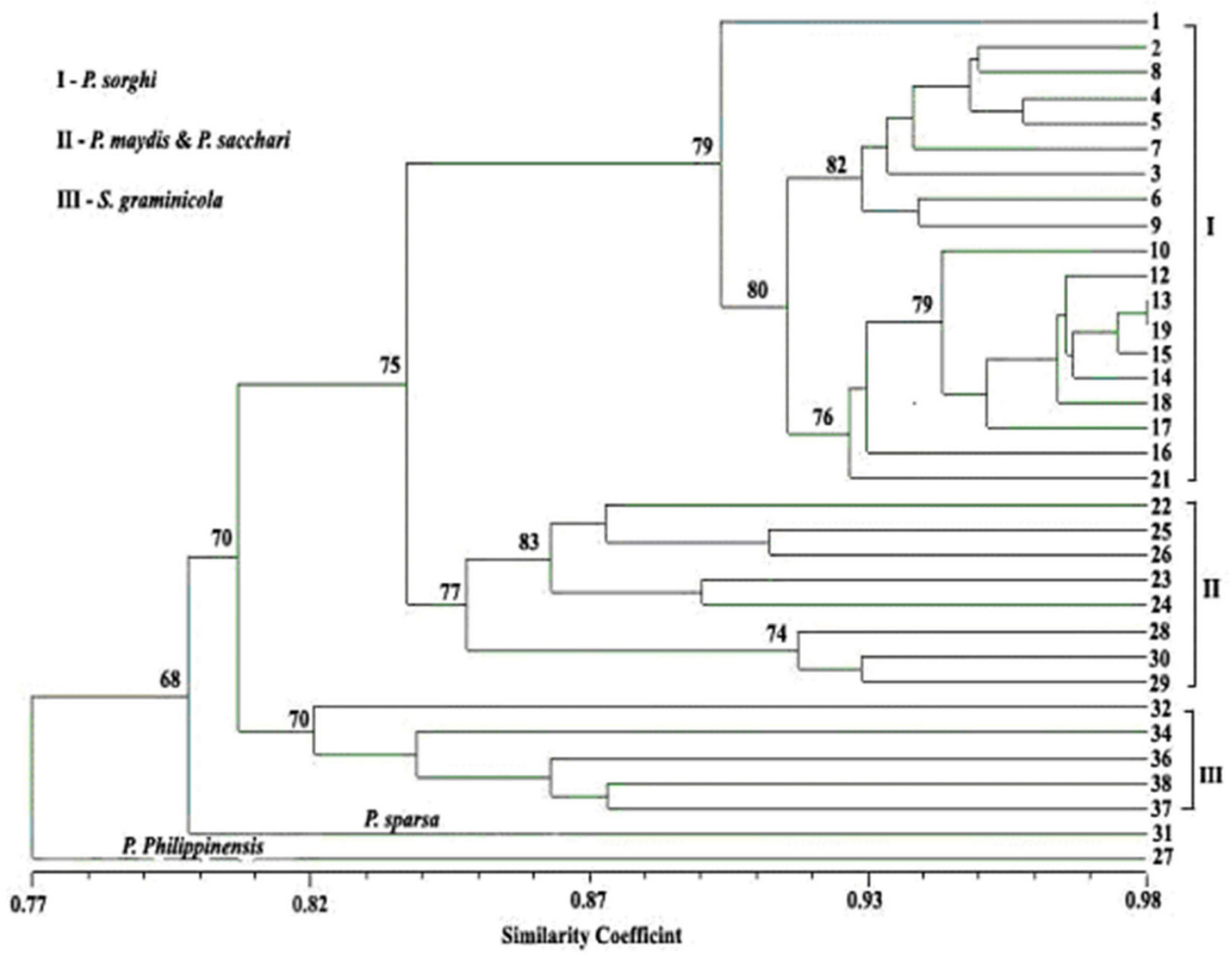

Figure 2

Cluster analysis. Dendrogram showing the clusters of 34 Peronosclerospora, Peronospora and Sclerospora isolates using 54 sorghum downy mildew microsatellites. Percentages from 1000 bootstrap replications are shown near the branches of each cluster.

high-pressure nebulizer, and a substantial portion of the clones were truncated within the microsatellite. The most frequent dinucleotide microsatellite motifs detected in our libraries were $(\mathrm{CA} / \mathrm{AC})_{\mathrm{n}}$ or $(\mathrm{GT} / \mathrm{TG})_{\mathrm{n}}$. followed by $(\mathrm{GA} / \mathrm{AG})_{\mathrm{n}}$ or $(\mathrm{CT} / \mathrm{TC})_{\mathrm{n}}$. In earlier studies, $(\mathrm{CA})_{\mathrm{n}}$ repeat motifs [47] and $(A G)_{n}$ repeat motifs [48] were also detected from the ascomycetes, Podospora anserina and Lobaria pulmonaria respectively. Approximately $39 \%$ of all isolated loci were composed of complex intermixed motifs, which were rarely arranged in a tandem way. This pattern, known as cryptic simplicity [49], is common in larger eukaryotic genomes [50]. Microsatellites identified with trinucleotide repeats (CAA, AGG and ACA) were found in this study with low frequencies, but seem to differ from those typically found in 14 fungal genomes (AAG, AAC, AGC, and ATC) [51]. One trinucleotide repeat clone (DM45) included multiple repeats in a complex pattern but no significant homology was found to other sequences currently in GenBank.

Determining if microsatellites will be polymorphic can only be assessed empirically, however, two considerations can help predict if polymorphism is likely. First, as slippage during replication increases with the number of tandem repeats [52], loci in which the motif is iterated at least eight times are desirable. Second, it may be possible to predict the stability of a given microsatellite motif by assessing the likelihood of "expandability" [53]. Microsatellites reflect a balance between expansion and contraction, but while there is evidence of a bias toward increasing microsatellite size [54], very long tandem repetitions are rare [55]. In contrast, in our study, (CA/AC)n 


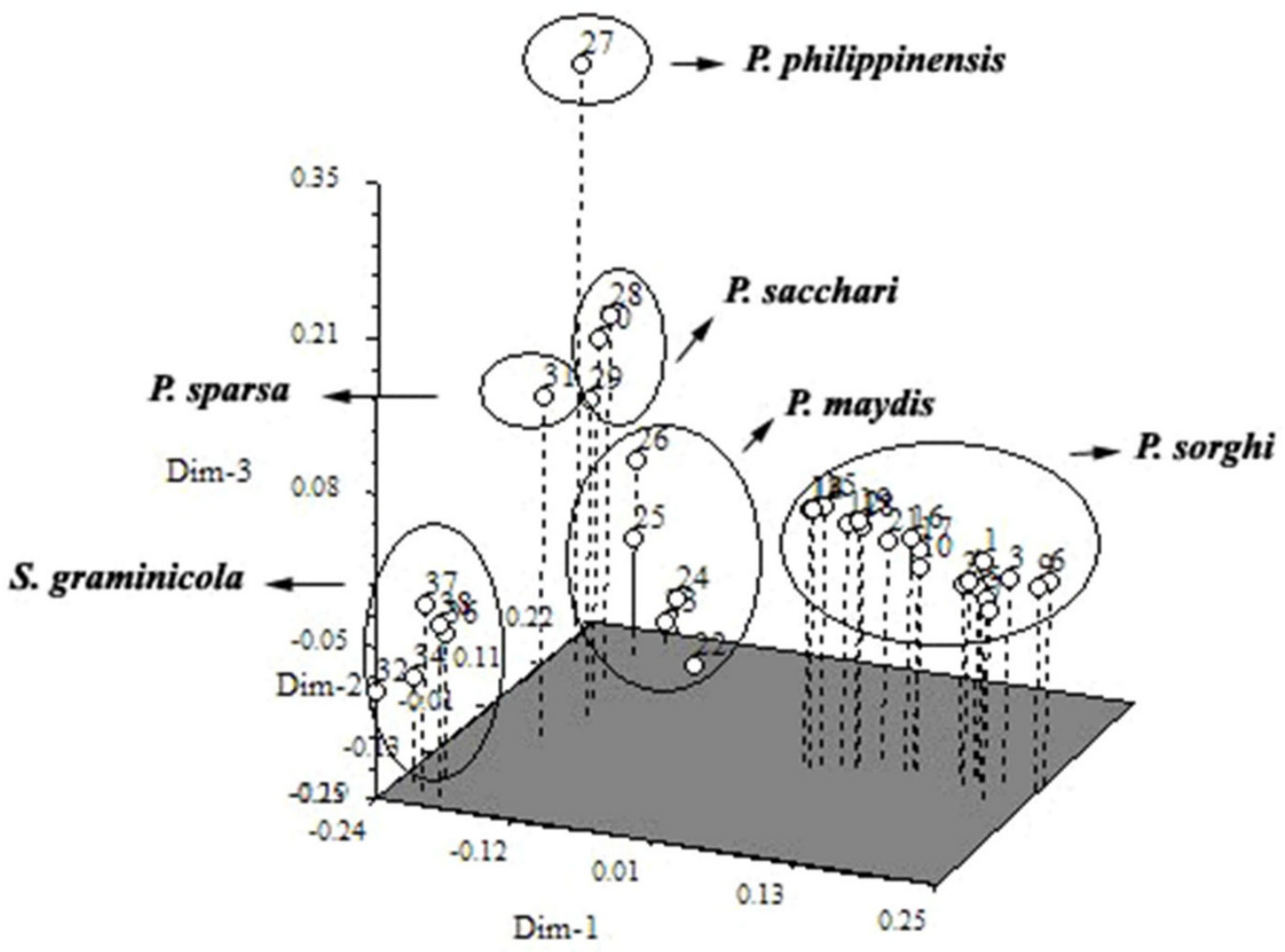

\section{Figure 3}

Principal coordinate analysis (PCA). Three-dimensional display of 34 Peronosclerospora, Peronospora and Sclerospora isolates based on the combination of data obtained with 54 SSRs. Dimensions I, 2 and 3 are accounted $86 \%$ of the variation observed.

and (GT/TG)n were commonly repeated more than 20 times, suggesting expansion to these lengths is not limited. The presence of these motifs in most fungal and oomycete genomes suggests they would be useful microsatellites to target in different species where genome data are not available.

\section{Retrotransposable Elements}

The presence of retrotransposon-like elements (mobile genetic elements) plays an important role in genome evolution and such elements constitute about 5 to $10 \%$ of the genome in eukaryotes [56]. DM55 (ACA) ${ }_{19}$ showed significant sequence homology to mitochondrial sequences in several Phytophora species (Table 3). Two of the P. sorghi SSR sequences were found to have a degree of similarity to reverse transcriptases, suggesting an origin from retro- transposons possibly present in a progenitor species. In this study, $P$. sacchari and $S$. graminicola isolates were not amplified with DM 21, whereas, DM53 cross amplified in all the species studied. These results suggest the GypsyPr2 reverse transcriptase-like gene sequence as defined in Phytopthora ramorum was not present in P. sacchari or $S$. graminicola isolates. However, sequences similar to the Phytopthora infestans GypsyPi-3a and GypsyPi-3b retrotransposon-like and to the GypsyPs-1A sequence from Phytopthora sojae were present in all Peronosclerospora, Peronospora and Sclerospora downy mildew isolates. Primers and probes built to take advantage of the presence of unique differences in such retrotransposon sequences can be useful for strain/race identification. Examples include the work by Sastryet al. [57] with S. graminicola and Becker et al. [58] in the basidiomycete Chondrostereum purpureum. 


\section{Gel analysis}

Resolving microsatellite amplicons in polyacrylamide gels using a LI-COR high throughput sequencing system with fluorogenic primers results in significantly more useful bands than resolving the same products in 4\% SFR gels stained with ethidium bromide. For example DM12, 19, 30 and 38 gave monomorphic expression in SFR agarose gels but showed alleles with polymorphic differences in LI-COR poly-acrylamide gels. Taken together, from combined data across 34 Peronosclerospora, Peronospora and Sclerospora spp. isolates, an average of 4.8 polymorphic markers were detected per SSR in LI-COR poly-acrylamide gels versus 2.7 in SFR agarose gels. Thus the use of LI-COR poly-acrylamide gels with fluorogenic labeled primers was more efficient in separating bands which reflect clear cut polymorphisms. Fingerprinting using 54 SSR primer pairs over all the isolates resulted in 260 diagnostic alleles. Although it is assumed that the majority of size variants (100 to $350 \mathrm{bp}$ ) was due to variation in the number of the repeat motifs, this has not been verified by sequencing. Insertions, deletions and base substitutions in the flanking regions [59] might also account for variation in fragment length, especially when amplicons from different species are compared.

\section{Cross-species amplification}

It has been shown that microsatellite primers developed for a distinct species can be useful for genetic analysis in closely related species [60], but successful transferability depends upon the evolutionary distance between source and target species [61]. Dutech et al. [62] reported relatively low cross-species transferability of microsatellites in fungi. Within genera, only $34 \%$ of the loci tested could be transferred, which appears much lower than in animals or plants. Here, twelve SSRs (DM 9, 12, 13, 14, 16, 19, 30, $31,35,49,53$ and DM54) were cross amplified in samples from 6 species of downy mildew-causing oomycetes. Successful cross-amplification simply indicates that the flanking regions are conserved across the species studied, but it does not tell anything about the character and structure of the fragment and additional sequencing will be necessary to clarify the structure of these fragments. Similar findings with successful cross amplification of SSRs in closely related species were reported for lichen-associated fungi [48] and in for a variety of fungal species [51]. Another interesting feature evident from our study is the distinctness of different species as revealed by unique banding patterns with different SSRs as evinced clearly from Fig. 1. Unique bands were noted with DM 3, 8, 11, 13, 18, 27, $31,39,40,45,50,52,53,54$, \& DM 55 for $P$. philippinensis and DM13, 23, 24, 45, 48, 50 and DM53 for P. sparsa. While these amplicons may be useful for diagnostics based on unique banding patterns, the information for $P$. philippinensis and P. sparsa is based on single isolates, so data from more independent, species-verified samples will be required to assess the degree of variation within natural populations. Based on the species-specific clustering of isolates where multiple samples were available, distinctive fingerprints can be anticipated.

\section{Cluster analysis}

In the present study, SSR markers revealed using high throughput LI-COR-NEN ${ }^{\circledR}$ Model 4300 -dual-dye automated DNA Analyzer have been used to resolve cryptic genetic variation of closely related different downy mildew species that have been impossible to resolve with morphological systematic characters. SSR fingerprinting was conducted using 54 primer pairs and genomic similarity analyses derived from qualitative data grouped isolates of samples of downy mildew according to host specificity (sorghum, maize, sugarcane, pearl millet and rose) whose taxa had been uncertain based on morphological criteria. In this study, metalaxyl sensitive P3 isolate (\#2 in Fig. 2) in cluster I grouped with all other metalaxyl resistant isolates, suggested that metalaxyl resistance may have originated in a P3 isolate to give rise to the recent outbreak, consistent with results of based on AFLP molecular characterization [15].

However, mating and recombination involving metalaxyl-resistant genotypes and other isolates, along with selection in favor of resistance would narrow the genetic base and can account for the high similarity (approximately 89\%) among all 19 P. sorghi isolates in cluster I. P. maydis and $P$. sacchari isolates in cluster II were grouped into two sub clusters with high similarity coefficient (approx. 82\%) indicates that corn and sugarcane downy mildew isolates have narrow genetic differences, showing more genetic similarities with each other than other Peronosclerospora species. The single isolates of $P$. philippinensis and P. sparsa were not grouped with any of the three clusters and showed their uniqueness due to their distinct banding pattern with different microsatellite primer combinations as detailed earlier. The three-dimensional comparison is compatible with cluster analysis and provides a good visual comparison of the genetic similarities and differences of the isolates. Fig. 3 clearly depicted the unique identity of $P$. philippinensis from other species. This display shows that the genetic distance between $P$. philippinensis and $P$. sacchai is very narrow. Similar findings with close phylogenetic relationship was recorded through isozyme analysis between $P$. philippinensis and $P$. sacchari isolates from Taiwan $[26,63]$ and by RFLP patterns by [13]. Further study is clearly needed to confirm this relationship. Unfortunately, the select agent status of $P$. philipinnensis has made the obtaining of additional samples, even of DNA, impossible to date.

\section{Conclusion}

Microsatellite primer sets developed from $P$. sorghi sequences proved to be useful for all downy mildew species analyzed and are likely to be increasingly developed 
and applied to studies of pathogen epidemiology, population biology, and genomics. The diversity of microsatellite motifs gave each species a unique "signature" of repeat distributions. Subsets of the 54 newly developed SSRs may be very useful for rapid and efficient identification and genetic analysis of the natural populations and host range of these obligate oomycetes. The unique banding pattern of $P$. philippinensis from fifteen (DM 3, 8, 11, 13, $18,27,31,39,40,45,50,52,53,54, \&$ DM 55) and $P$. sparsa from seven (DM13, 23, 24, 45, 48, 50 and DM53) SSRs make these primers useful as diagnostic markers for the respective species. In future studies it will be possible to focus on the population diversity and recombination within and between native and introduced populations of the closely related species. These distinct fingerprinting profiles can be used as diagnostic tools to formulate breeding strategies targeting host resistance to local pathogen populations and for monitoring the emergence of new virulent races.

\section{Authors' contributions}

RP performed the capturing of microsatellites, data analysis and wrote the manuscript. PN and UKR provided lab facilities and assisted in capturing microsatellites. RP and SRE carried out all gel analyses. EGN performed sequence analysis. LKP, GNO, DGL and CWM provided the source materials. DGL and CWM directed and oriented the project and revised the manuscript. All authors read and approved the final manuscript.

\section{Additional material}

\section{Additional file 1}

Information on 55 SDM (Peronosclerospora sorgi) microsatellites loci. Microsatellite loci repeat motif, primer sequence (forward and reverse), allele size, annealing temperature $\left(T_{a}\right)$, number of alleles detected and gene bank accession numbers.

Click here for file

[http://www.biomedcentral.com/content/supplementary/14712156-9-77-S1.xls]

\section{Acknowledgements}

This research was supported by a USDA cooperative agreement and a Texas Cropping System grant from the Texas Agricultural Experiment Station.

\section{References}

I. Food and Agriculture Organization of the United Nations [http://www.fao.org]

2. Butler EJ: Some diseases of cereals caused by Sclerospora graminicola. Memoirs of the Department of Agriculture. India Botanical Series 1907, 2: I-24.

3. Williams R, Dange S, Mughogho L, Rao K: Identification of QL-3 sorghum: A source of resistance to Peronosclerospora sorghi. Plant Disease 1982, 66:807-809.

4. Jegera MJ, Gilijamsea E, Bockb CH, Frinkinga HD: The epidemiology, variability and control of the downy mildews of pearl millet and sorghum, with particular reference to Africa. Plant Pathology 1998, 47:544-569.

5. Williams R: Downy mildew of tropical cereals. Advances in Plant Pathology 1984, 3: I- 103.

6. Isakeit T, Odvody G, Jahn R, Deconini L: Peronosclerospora sorghi resistant to metalaxyl treatment of sorghum seed in Texas. Phytopathology 2003, 93:S39.

7. Exconde OR, Raymundo AD: Yield loss caused by Philippine corn downy mildew. Philipp Agric 1974, 58: I I5-I 20.

8. Weston WHJ: Philippine downy mildew of maize. J Agric Res 1920, 19:97-122.

9. Exconde OR, Elec JV, Advincula BA: Host range of Sclerospora philippinensis Weston in the Philippines. Philipp Agric 1968, 52:175-188.

10. Weston WHJ: Another conidial Sclerospora of Philippine maize. J Agric Res 1921, 20:669-684.

II. Bock C, Jeger M, Mughogo L, Cardwell K, Mtisi E, Kaula G, Mukansbima D: Variability of Peronosclerospora sorghi isolates from different geographic locations and hosts in Africa. Mycological Research 2000, 104:61-68.

12. Bock C, Jeger M, Mughogo L, Mtisi E, Cardwell KF: Production of conidia by Peronosclerospora sorghi in Zimbabwe. Plant Pathology 1998, 47:243-25I.

13. Yao C, Magill CW, Frederiksen RA: An AT -Rich DNA Clone is Species-Specific for Identification of Peronosclerospora sorghi. Applied and Environmental Microbiology I991, 57:2027-2032.

14. Yao C, Frederiksen RA, Magill CW: Length heterogeneity in ITS 2 and the methylation status of CCGG and GCGC sites in the rRNA genes of the genus.Perosclerospora. Current Genetics I 992, 22:415-420.

15. Perumal R, Isakeit T, Menz M, Katile S, No EG, Magill CW: Characterization and genetic distance analysis of isolates of Peronosclerospora sorghi using AFLP fingerprinting. Mycological Research 2006, I I0(4):47|-478.

16. Jeffreys AJ, Wilson V, Thein SL: Hypervariable 'minisatellite' regions in human DNA. Nature 1985, 3 I 4(6006):67-73.

17. Tautz $D$, Renz M: Simple sequences are ubiquitous repetitive components of eukaryotic genomes. Nucleic Acids Res 1984, I 2( I 0):41 27-4I 38.

18. Queller DC, Strassmann JE, Hughes CR: Microsatellites and kinship. Tree 1993, 8:285-288.

19. Taylor JW, Jacobson DJ, Fisher MC: The evolution of asexual fungi: reproduction, speciation and classification. Annu Rev Phytopathol 1999, 37:197-246.

20. Bart-Delabesse E, Sarfati J, Debeaupuis JP, van Leeuwen W, van Belkum A, Bretagne S, Latge JP: Comparison of restriction fragments length polymorphism, microsatellite length polymorphism, and random amplification of polymorphic DNA analyses fingerprinting Aspergillus fumigatus isolates. J Clin Microbiol 200I, 39:2683-2686.

21. Perez MA, Gallego FJ, Martinez I, Hidalgo P: . Detection, distribution and selection of microsatellites (SSRs) in the genome of the yeast Saccharomyces cerevisiae as molecular markers. Lett Appl Microbiol 2001, 33:46I-466.

22. Brondani C, Brondani RPV, Garridon LR, Ferreira ME: Development of microsatellite markers for genetic analysis of Magnaporthe grisea. Genet Mol Biol 2000, 23:753-762.

23. Kaye C, Milazzo J, Rozenfeld S, Lebrun MH, Tharreau D: The development of simple sequence repeat markers for Magnaporthe grisea and their integration into an established genetic linkage map. Fungal Genet Biol 2003, 40(3):207-2I4.

24. Lees AK, Wattier R, Shaw DS, Sullivan L, Williams NA, Cooke DEL: Novel microsatellite markers for the analysis of Phytophthora infestans populations. Plant Pathology 2006, 55:3 II-319.

25. Garnica DP, Pinzon AM, Quesada-Ocampo LM, Bernal AJ, Barreto E, Grunwald NJ, Restrepo S: Survey and analysis of microsatellites from transcript sequences in Phytophthora species: frequency, distribution, and potential as markers for the genus. BMC Genomics 2006, 7:245.

26. Bonde MR, Peterson GL, Dowler WM, May B: Isozyme analysis to differentiate species of Peronosclerospora causing downy mildew of maize. Phytopathology 1984, 74:1278-1283.

27. Kijas JM, Fowler JC, Garbett CA, Thomas MR: Enrichment of microsatellites from the citrus genome using biotinylated oligonucleotide sequences bound to streptavidin-coated magnetic particles. Biotechniques 1994, I 6(4):656-660. 662. 
28. Prochazka M: Microsatellite hybrid capture technique for simultaneous isolation of various STR markers. Genome Res 1996, 6(7):646-649.

29. Reddy OUK, Pepper AE, Abdurakhmonov I, Saha S, Jenkins JN Brooks T, Bolek Y, El-Zik KM: New Dinucleotide and Trinucleotide Microsatellite Marker Resources for Cotton Genome Research. The Journal of Cotton Science 2001, 5: I03-II3.

30. Simple Sequence Repeat Identification Tool (SSRIT) database [http://www.gramene.org/db/searches/ssrtool]

31. Genomic BLAST databases [http://blast.ncbi.nlm.nih.gov/ Blast.cgi]

32. Primer3 (v. 0.4.0) Pick primers from a DNA sequence [http:/ /fokker.wi.mit.edu/primer3/input.htm]

33. Sneath PHA, Sokal RR: Numerical Taxonomy. The Principles and Practices of Classification. San Francisco: W.H. Freeman and Co; 1973.

34. Swofford DL: PAUP*: Phylogenetic Analysis Using Parsimony (*and other Methods). Sunderland, MA: Sinauer Associates; 2002.

35. Rohlf FJ: NTSYS-pc Numerical Taxonomy and Multivariate Analysis System. Volume I. Version 2.I New York. USA: Exeter Publications; 2000

36. Frederiksen RA, Renfro BL: Global status of maize downy mildew. Annu Rev Phytopathol 1977, I 5:249-275.

37. Shaw CG: Peronosclerospora species and other downy mildews of the gramineae. Mycologia 1978, 70:594-604.

38. Siradhana BS, Dange SRS, Rathore RS, Singh SD: A new downy mildew on maize in Rajasthan. India Curr Sci 1980, 49:316-317.

39. Schmitt CG, Woods JM, Shaw CG, Stansbury E: Comparison of some morphological characters of several corn downy mildew incitants. Plant Dis Rep 1979, 63:621-625.

40. Bonde M, Peterson G, Kenneth R, Vermeulen H, Sumartini Bustaman $M$ : Effect of temperature on conidial germination and systemic infection of maize by Peronosclerospora species. Phytopathology 1992, 82: 104-109.

41. Micales JA, Bonde MR, Petersen GL: Isozyme analysis and aminopeptidase activities within the genus Peronosclerospora. Phytopathology 1988, 78:|396-1402.

42. Legg EJ: Molecular diagnosis of temperate and tropical downy mildews. Downy Mildews Newsletter 1996, 9:3-4.

43. Anaso AB, Tyagi PD, Emechebe AM, Manzo SK: Identity of downy mildew in maize in Nigerian Guinea savannah. Samaru Journal of Agricultural Research 1987, 5:13-23.

44. Goldstein DB, Schlötterer C: Microsatellites-Evolution and Applications. New York: Oxford University Press; 1999.

45. Zane L, Bargelloni L, Patarnello T: Strategies for microsatellite isolation: a review. Mol Ecol 2002, I I (I): I- I6.

46. Connell JP, Pammi S, lqbal MJ, Huizinga T, Reddy AS: A high through-put procedure for capturing microsatellites from complex plant genomes. Plant Mol Biol I 998, I 6:34 I-349.

47. Khashnobish A, Hamann A, Osiewacz HD: Modulation of gene expression by (CA)n microsatellites in the filamentous ascomycete Podospora anserina. Appl Microbiol Biotechnol 1999, 52(2): $191-195$.

48. Walser JC, Sperisen C, Soliva M, Scheidegger C: Fungus-specific microsatellite primers of lichens: application for the assessment of genetic variation on different spatial scales in Lobaria pulmonaria. Fungal Genet Biol 2003, 40(I):72-82.

49. Tautz D: Hypervariability of simple sequences as a general source for polymorphic DNA markers. Nucleic Acids Res 1989 I 7( 1 6):6463-647I.

50. Hancock JM: Simple sequences and the expanding genome. Bioessays 1996, 18:421-425.

51. Lim S, Notley-McRobb L, Lim M, Carter DA: A comparison of the nature and abundance of microsatellites in 14 fungal genomes. Fungal Genet Biol 2004, 4 I (I I ): I 025-I036.

52. Pupko T, Graur D: Evolution of microsatellites in the yeast Saccharomyces cerevisiae : role of length and number of repeated units. J Mol Evol 1999, 48(3):313-316

53. Tóth G, Gaspari Z, Jurka J: Microsatellites in different eukaryotic genomes: survey and analysis. Genome Res 2000, 10:967-98I.

54. Zhu Y, Strassmann JE, Queller DC: Insertions, substitutions, and the origin of microsatellites. Genet Res 2000, 76(3):227-236.

55. Nielsen R, Palsboll PJ: Single-locus tests of microsatellite evolu tion: multi-step mutations and constraints on allele size. Phylogen Evol 1999, I I:477-484.
56. Bingham PM, Zachar Z: Retrotransposons and the FB transposon from Drosophila melonogaster. Washington: ASM Publications; 1989.

57. Sastry JG, Ramakrishna W, Sivaramakrishna S, Thakur RP, Gupta VS Ranjekar PK: DNA fingerprinting detects genetic variability in the pearl millet downy mildew pathogen (Sclerospora graminicola). Theor Appl Genet 1995, 91:856-86|.

58. Becker EM, Bastide PY, Hintz WE: A retrotransposon-like element and its occurrence in British Columbia populations of Chondrostereum purpureum. Fungal Genet Biol 2004, 4 I ( 1 0):921-929.

59. Peakall R, Gilmore S, Keys W, Morgante M, Rafalski A: Cross-species amplification of soybean (Glycine max) simple sequence repeats (SSRs) within the genus and other legume genera: implications for the transferability of SSRs in plants. Mol Biol Evol 1998, I 5( I 0): I 275- I 287.

60. Davis CS, Strobeck C: Isolation, variability, and cross-species amplification of polymorphic microsatellite loci in the family Mustelidae. Molecular Ecology 1998, 7:1776-1778.

6I. Rosetto M: Sourcing of SSR markers from related plant species. Wallingford: CABI Publishing; 200I.

62. Dutech C, Enjalbert J, Fournier E, Delmotte F, Barres B, Carlier J, Tharreau D, Giraud T: Challenges of microsatellite isolation in fungi. Fungal Genet Biol 2007, 44( 1 0):933-949.

63. Bonde MR, Peterson GL: Comparison of host ranges of Peronosclerospora philippinensis and $\boldsymbol{P}$. sacchari. Phytopathology 1983 73:875-878.
Publish with Bio Med Central and every scientist can read your work free of charge

"BioMed Central will be the most significant development for disseminating the results of biomedical research in our lifetime. "

Sir Paul Nurse, Cancer Research UK

Your research papers will be:

- available free of charge to the entire biomedical community

- peer reviewed and published immediately upon acceptance

- cited in PubMed and archived on PubMed Central

- yours - you keep the copyright
BioMedcentral 